\title{
An ideal media for the in-vitro propagation of Ipomoea palmata Forssk. [Synonym - Ipomoea cairica. L. Sweet] Convolulaceae
}

\author{
Leena Jacintha Stephen ${ }^{1 *}$, A.K.Bopaiah ${ }^{2}$. \\ Department of Botany Research and Development Centre,,Bharathiyar University, Coimbatore, Tamil Nadu, India. \\ Department of Botany, St.Josephs Post Graduate and Research Centre. Langford Road, Richmond Town, Bangalore- \\ 560027, Karnataka, India.
}

\begin{abstract}
In order to study its development in-vitro, an investigation was carried out to determine and establish a suitable media for the growth of Ipomoea palmata Forssk, [Ipomoea. cairica]. Aerial parts of a healthy plant were chosen as explants. Callogenesis of these leaf, stem and flower explants was initiated on three different media namely Murashige and Skoog (1962) media, Gamborg or B5 (1968) media and White's media, (1963). These basal media were supplemented with a quantity of coconut water and with various combinations of growth hormones- 2,4-Dichlorophenoxyacetic acid (2,4- D), Indole Acetic acid (IAA), Indole Butyric Acid (IBA) and 6-Benzyl amino purine (BA). The observation showed that the explants regenerated into profuse calli which eventually proliferated into multiple shoots. Root formation from the callus was also observed. The highest response in callogenesis and morphogenesis was observed in M.S basal media supplemented with $4 \mathrm{mg} / \mathrm{l} B A$ and $1 \mathrm{mg} / \mathrm{l}$ 2,4-D. However development was first noticed in B5 basal media supplemented with $4 \mathrm{mg} / \mathrm{l}$ and $1 \mathrm{mg} / \mathrm{l}$ 2,4-D. I. palmata responded positively recording rapid growth, thereby, demonstrating both Re and De differentiation. Among the three different media, the low-salt media i.e. White's media showed a relatively poor response in callus and plantlet formation. Interestingly I.palmata seemed to have a great affinity for both MS and B5 media specifically, the hormonal concentration mentioned above. This report of a positive in-vitro response of I.palmata has not been published before.
\end{abstract}

Keywords: callogenesis, dedifferentiation, explants, redifferentiation, shoot morphogenesis,

\section{Introduction}

Ipomoea commonly known as "Morning Glory" comprises the largest genus of the family Convolulaceae with approximately 600-700 species. Their natural trailing habitat ranges from high-climbing vines to prostrate perennials. They grow in abundance on walls, fences and trees. With their brightly coloured, funnel shaped flowers they are often grown as ornamentals. Several vines of this family are cultivated for their nutritious roots and foliage. Tradition shows an interesting use of Ipomoea in religious rituals in some parts of the world.[ 1]

Some species of this genus have found a place in the medical world as an effective cure for diseases such as diabetes, hypertension, dysentery, constipation, fatigue, arthritis, rheumatism, hydrocephaly, meningitis, kidney ailments and inflammations. Some species have showed antimicrobial, analgesic, spasmolitic, spasmogenic, hypoglycemic, hypotensive, anticoagulant, anti-inflammatory, psychotomimetic and anticancer activities.[2] The most common use of the roots of Ipomoea species is to treat constipation (Pereda-Miranda \& Bah, 2003).

Ipomoea palmata. or I.cairica - commonly called 'Rail road vine', is a climbing herb and is found growing in the tropical and subtropical regions of the world. This perennial gets its name from the unique palmshaped leaves. It bears fairly large, attractive flowers which range from white to lavender in colour. The mature fruit is small measuring close to $1 \mathrm{~cm}$ across and contain hairy seeds. [3] This plant shows high sun tolerance, high disease and pest tolerance. This could probably be the reason behind its relatively fast growth rate that it is sometimes considered a noxious or invasive weed.

Despite the ease of its natural growth and propagation, its diminishing numbers are a cause for concern. The reason could be the dwindling forests due to excessive urbanization. Having established its potential as a medicinal plant and addressing its alarming disappearance, an in-vitro propagation has become a natural choice for its conservation. This paper is aimed at proposing an effective strategy for the conservation and production of calli which would serve as an effective source for further studies. [4]

Further, only some of the most economical species of Ipomoea eg: I.batatas and I.aquatica have been investigated for their in- vitro activity, so a lab trial needs carried out for this particular species.[5] 


\section{Material And Methods}

I.palmata was collected from St. Thomas Town, Bangalore, India.

All collected plant material was maintained at St.Josephs' Research Centre, Bangalore. The study was carried out at St. Joseph's Research Centre, Langford Road, Richmond Town, Bangalore. Karnataka, India.

Different aerial parts of a healthy plant, showing no traces of nutritional or water stress, were selected as explants - apical meristems, nodal regions, young tender leaves, petioles, pedicels, petals and sepals. Studies have proved that there are greater possibilities of obtaining positive responses if the explants are young and tender.[6]

These explants were put through a series of sterilization procedures to minimize the risk of contamination, both bacterial and fungal. The initial step involved the washing of explants in soap water to remove surface contaminants followed by washing thoroughly in 10\% Tween.-20 They were then rinsed four times in double distilled water to remove excess disinfectant and taken inside the Inoculation chamber [ LAF]. The plant parts were treated with $1 \%$ mercuric chloride solution for 15 minutes, followed by several rinses in double distilled water to remove all traces of mercuric chloride. They were then dipped for a few seconds in Hydrogen peroxide after which the explants were then ready for inoculation.

Since the current study involved a comparative analysis for a suitable media for micropropagation, three types of basal media were used in the work reported here.

Murashige-Skoog (1962) basal media supplemented with $100 \mathrm{ml} / \mathrm{l}$ tender coconut water, was further divided into MS 1 and MS 2.

The MS 1 media had the hormones - IAA -4mg/l and BA $-4 \mathrm{mg} / \mathrm{l}$ added to it. The MS 2 media had $4 \mathrm{mg} / \mathrm{l}$ BAP and $1 \mathrm{mg} / \mathrm{l}$ of 2,4-D. added to it.

Similarly the second and third media used were B5 or Gamborg Media (1968) and White's media. These basal media were also supplemented with the same components as MS media mentioned above.

Thus, these 6 different media compositions [MS-1, *MS-2, B5 -1, **B5-2, WM-1 and WM-2] had the same hormones and the same concentration. [Table -1]

One more media formulation with double the concentration of hormones was prepared with one alteration of using Indole Butyric Acid instead of IAA.

This second set of media was supplemented with $8 \mathrm{mg} / 1$ BAP, $8 \mathrm{mg} / 1 \mathrm{IBA}$ and $2 \mathrm{mg} / 12,4-\mathrm{D}$. These were labeled II MS -1, II MS-2, II B5-1, II B5-2, II WM- I and II WM-2 [Table 1].

III. TABLE -1

LIST OF MEDIA USED, ITS SUPPLEMENTS AND THEIR QUANTITIES.

\begin{tabular}{|c|c|c|c|c|}
\hline Sl.No. & Type of media & Auxin $[\mathrm{mg} / \mathrm{l}]$ & Cytokinin [mg/l] & Growth promoter $[\mathrm{ml} / 1]$ \\
\hline 1. & I MS -1 & $\mathrm{IAA}-4 \mathrm{mg} / \mathrm{l}$ & BAP - $4 \mathrm{mg} / \mathrm{l}$ & Coconut water $100 \mathrm{ml} / \mathrm{l}$ \\
\hline 2. & I MS - 2 & $2,4-\mathrm{D}-1 \mathrm{mg} / \mathrm{l}$ & , & , \\
\hline 3. & I B5 - 1 & IAA $-4 \mathrm{mg} / \mathrm{l}$ & ", & , \\
\hline 4. & I B5 - 2 & $2,4-\mathrm{D}-1 \mathrm{mg} / \mathrm{l}$ & ", & , \\
\hline 5. & I WM - 1 & IAA $-4 \mathrm{mg} / \mathrm{l}$ & ", & , \\
\hline 6. & I WM - 2 & $2,4-\mathrm{D}-1 \mathrm{mg} / \mathrm{l}$ & , & , \\
\hline 7. & II $\quad$ MS -1 & $\mathrm{IBA}-8 \mathrm{mg} / \mathrm{l}$ & $\mathrm{BAP}-8 \mathrm{mg} / \mathrm{l}$ & , \\
\hline 8. & II $\mathrm{MS}-2$ & $2,4-\mathrm{D}-2 \mathrm{mg} / \mathrm{l}$ & , & , \\
\hline 9. & II $\quad$ B5 -1 & IBA $-8 \mathrm{mg} / \mathrm{l}$ & ", & , \\
\hline 10. & II B5 - 2 & $2,4-\mathrm{D}-2 \mathrm{mg} / \mathrm{l}$ & ", & 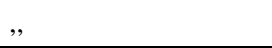 \\
\hline 11. & II WM - 1 & IBA $-8 \mathrm{mg} / \mathrm{l}$ & ", & , \\
\hline 12. & II WM - 2 & $2,4-\mathrm{D}-2 \mathrm{mg} / \mathrm{l}$ & ", & , \\
\hline
\end{tabular}

Inside the laminar airflow hood, inoculation was carried out in all the twelve media compositions. The leaf explants were inoculated separately on both the surfaces [dorsal and ventral surfaces in contact with the media]. Small incisions were made across the leaf before inoculation. The petioles of the leaf, sepals and petals [which have been taken from the bud- to reduce the occurrence of contamination], shoot apices and nodal regions were all tried as explants. Leaf initials were carefully removed and also used.

The cultures were then incubated in the Growth Room and maintained under controlled conditions, with the temperature at $25^{0} \mathrm{C}+/-2$ under a 16:8 hr light : dark photoperiod and illuminated with 1000 lux. white florescent light.

Frequent observations were recorded. 


\section{Results}

This species displayed a phenomenal success rate recording a positive response in both the "high salt" concentration media designated as MS 1 and MS -2, B5 1 and B5- 2. Plants showed negligible response in White's media.

\section{Media ONE - MS Media :}

Callus was first observed in the leaf explants [placed both on the dorsal and ventral surfaces]. Similarly callusing was also noticed in the petal explants. This took place in about 24 days. 33 days later a large leaf and shoot formation was seen form the callus cells [Fig -1]

Callus was also observed in a stem with leaf [MS-2], leaf initial [S-2], leaf ventral [MS-1 and MS-2]

Around 38-40 days later, multiple shoots were seen growing from the calli of the node with leaf explants in both MS-1 and MS-2 media [Fig-2].

Callus and slender, multiple shoots were seen in apical meristem explants [MS-2]. [Fig- 3]

Eventually callus and multiple shoots were also seen in petal [MS -2] leaf initial [MS-2] and petiole [ MS-2] and apical shoot [MS-2]. [Fig-4 ]

About 50 days later, after a second sub-culturing, from the apical meristem, an elongated shoot grew to touch the cap of the bottle in MS-2 media. [Fig -5]

The plantlet was subsequently sub-cultured but before the process, the longest shoot was measured to observe the rate of growth and it measured $26 \mathrm{~cm}$. [Fig-6]

Roots began to appear after three months in the callus of leaf initial. [MS-2]

For the second type of media i.e. II MS-1 and II MS-2, callus was seen first in leaf initial [II MS-2], apical meristem [II MS-2] and petiole [II MS-2]. This development was seen in about 26 day's time.

\section{Media TWO - B5 or GAMBORG MEDIA_:}

Callus growth was seen in leaf placed on the ventral surface, shoot tip and pedicel. This development was seen around 23 days after inoculation. About 32 days later callus along with multiple shoots were seen in leaf with petiole [ B5-1 and B5-2]. More callus was seen in pedicel [B5-1].

Callus in the leaf placed on the dorsal surface,[B5-2] formed primarily at the margins of the leaf, and at the regions of incision.[Fig -8]

A second and third trial was conducted to validate and then elucidate the quick appearance of plantlets, wherein inoculations were carried out and subsequent observation made on a regular basis. Around 20 to 22 days after inoculation a young plantlet with multiple stems along with leaves was observed in the node explant. This was seen in the B5-2 media. This was allowed to grow uninterrupted and after about 60 days, the length of the stem was calculated in the LAF.

A small plantlet was also observed in the leaf initial in B5-1 media.

Eventually there were plantlets seen in young leaf [B5-1], multiple shoots in leaf initial [B5-2], pedicel [B5-2] [Fig- 9] and a tiny shoot in leaf with petiole [B5-1].

It took about three months for roots to develop form the callus of pedicel [B5-2], leaf with petiole [B5-2] and shoot tip [B5-2]

Within a month, callus, leaves and shoots appeared in all the sub-cultured plantlets of the above mentioned explants

For the second type of media i.e. II B5-1 and II B5-2 callus and tiny green plantlets was seen in about 25 days. The first to show differentiation was the leaf with lateral bud [ II B5-2], node [ II B5-1] and the apical meristem explants [ II B5-1] .

\section{MEDIA THREE - WHITE'S MEDIA}

This media displayed a relatively poor response for all explants. The explants showed very little to no response in this media.

The reason for negligible growth could be lesser quantity of salts as compared to the other two media compositions 


\section{The following are photographs taken at every step of development.}

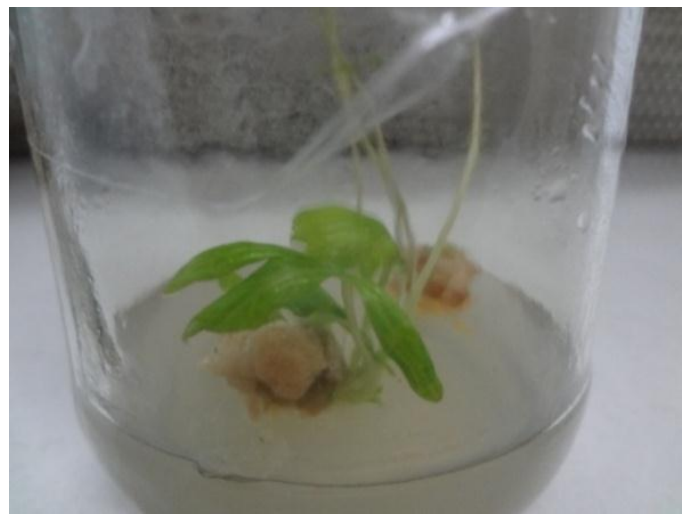

Fig-1: Leaf and shoot formation seen in Petal explant.

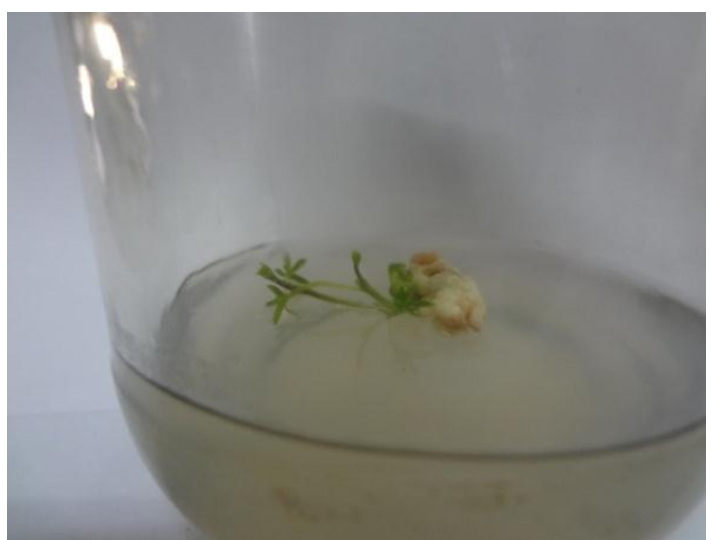

Fig-3: Slender shoot from apical meristem

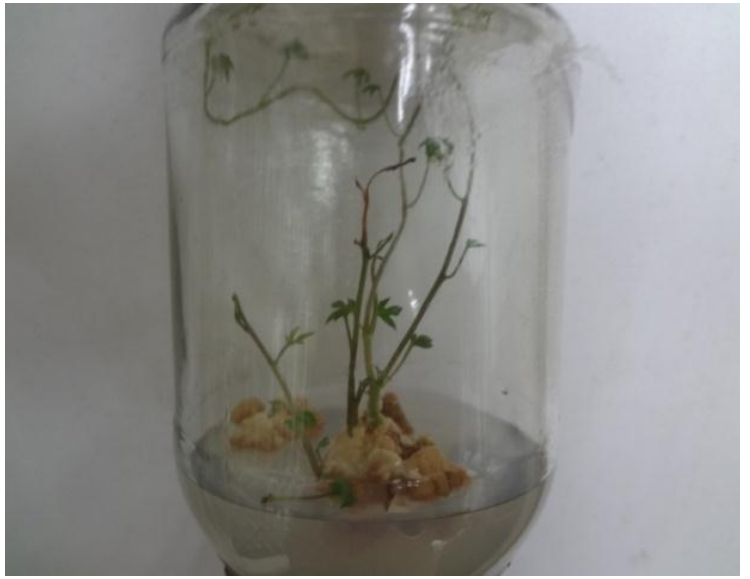

Fig-5: Multiple shoot formation

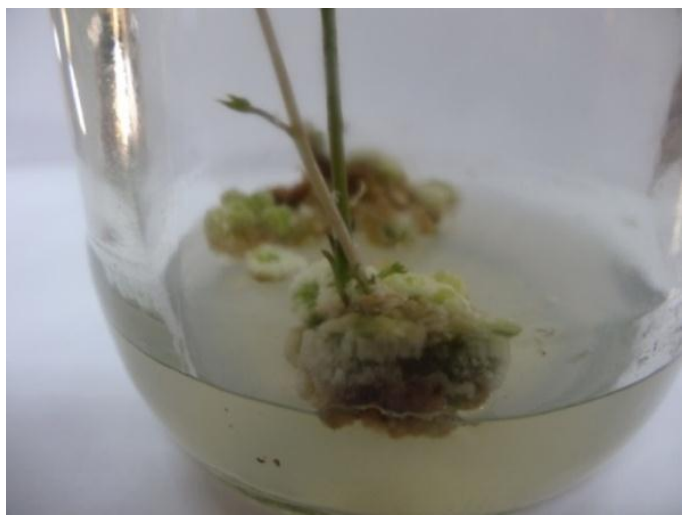

Fig-2:Calli and multiple shoots in node explant

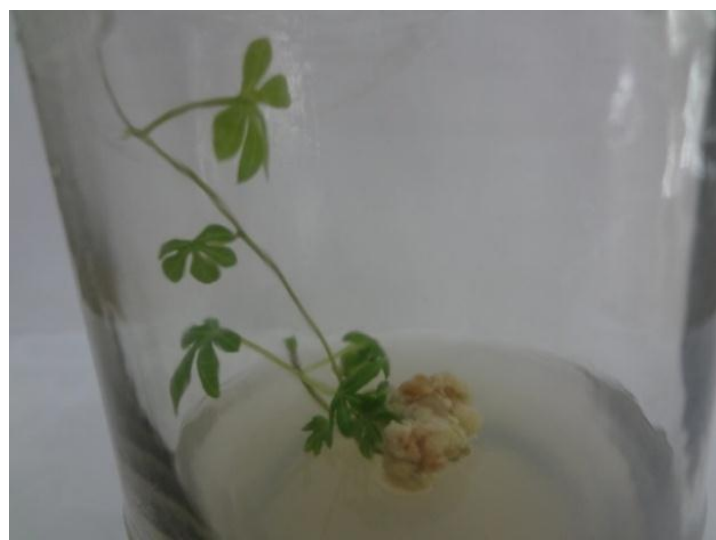

Fig-4: Shoot elongation

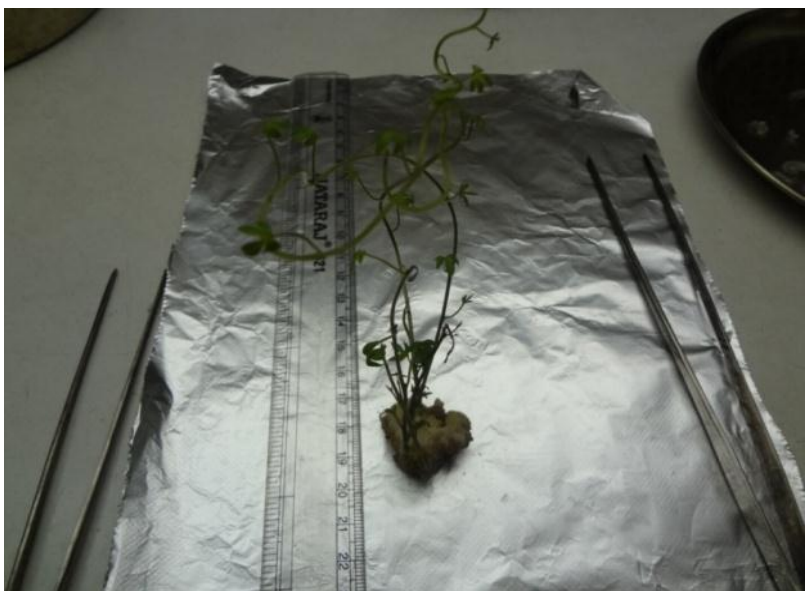

Fig-6: Prior to subculturing 


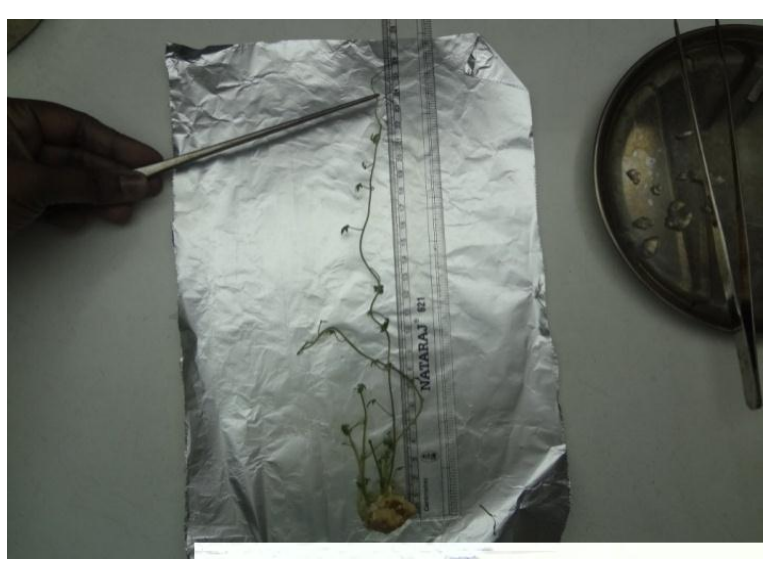

Fig-7: Longest shoot measuring $26 \mathrm{~cm}$

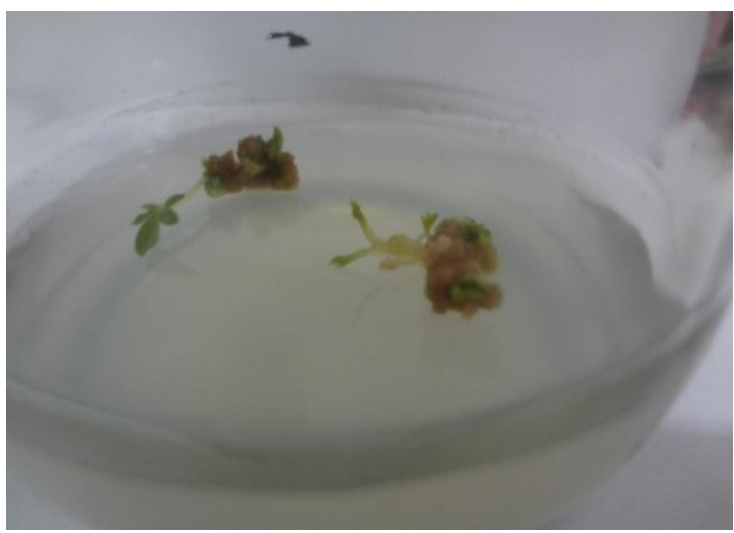

Fig- 9: Callus and tiny shoots from pedicel

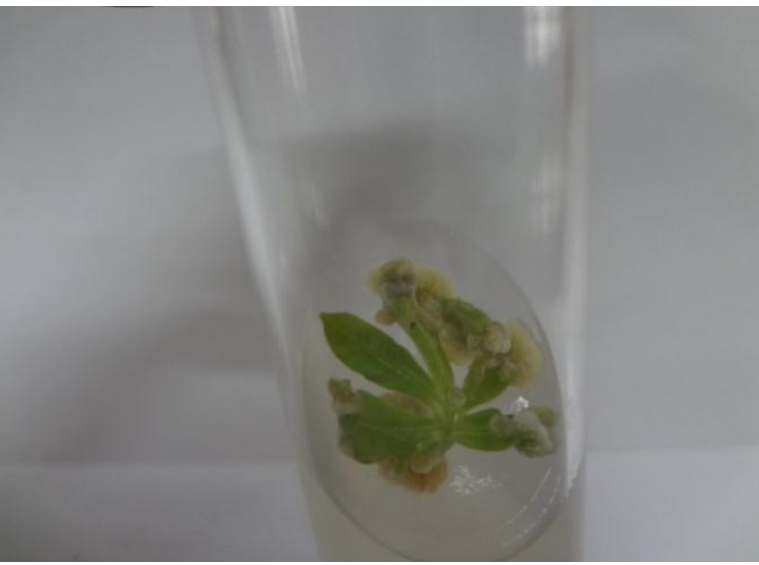

Fig-8: Callus at the margin of the leaf.

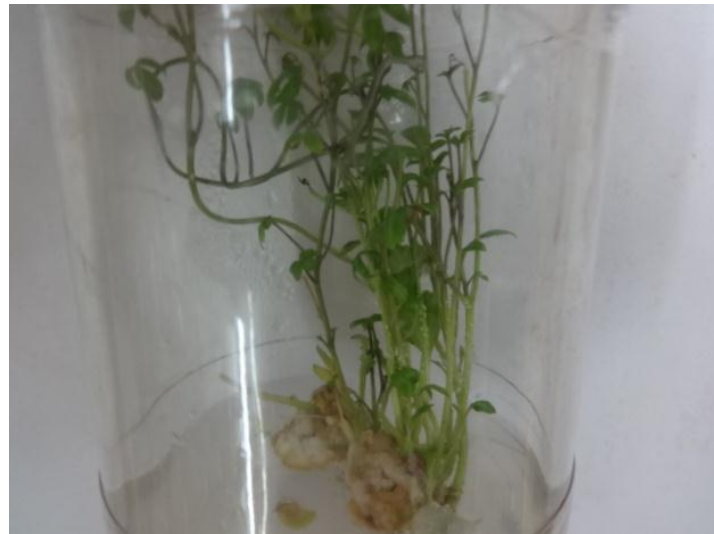

Fig-10: Abundant proliferation of shoots.

\section{Discussion}

In order to augment the understanding of I.palmata's growth and development in-vitro, this experiment was first aimed at standardizing a suitable media for its micropropagation. Therefore investigative studies were performed, which revealed a significant growth rate.

The MS and B5 basal media which were both fortified with 100ml/1 coconut water, 4mg/l BA, 4mg/l IAA and $1 \mathrm{mg} / 1$ 2,4-D showed the best results. These two basal culture media commonly called as 'high salt media' favored callus formation and promoted shoot proliferation.

Maximum morphogenesis was recorded in MS-2 media which showed multiple shoots growing in abundance from the callus.[ Fig-10] But the media which yielded positive results at a slightly faster rate was the B5 -2 media.

The MS-2 and B5-2 media contained the Auxin 2,4-D and the Cytokinin BAP. Studies have shown, and this experiment has proved that this is an ideal combination for the rapid callus and plantlet growth of this particular species. Auxins play an important role in many aspects of growth and differentiation. Cell division, cell enlargement, apical dominance are a few processes directly influenced by auxins.[ 8].

The auxin 2,4-D is a good callus inducer. Being a synthetic auxin it has been proved to be more stable that IAA [ the naturally occurring hormone used in MS-1 and B5-1]. The cytokinin BAP has been used to promote cell division, proliferation and shoot morphogenesis.[9]

Coconut milk or tender coconut water contains a growth factor called diphenylurea which exhibits cytokininlike responses.[10]

Further subculturing established profuse proliferation of calli and abundant shoot multiplication in the same media composition. Subsequent transflasking also resulted in rapid multiplication. Root initiation was also noticed from some callus cells. This can be attributed to the high auxin concentration [4mg/l IAA and $1 \mathrm{mg} / 1$ 2,4-D] in the media. 
All the three explants [ leaf, stem and flower] showed a similar, high percent of growth within two to three months of inoculation. However, as observed and reported earlier in most other species, the shoot apex recorded maximum growth and development.

Of all the three media used in the investigation White's media did not show any significant response in callus and plantlet regeneration.

The second set of media formulation namely II MS, II B5 and II WM did respond positively but at much a slower rate. These had a higher hormonal concentration as compared to the first set proving that a higher hormone concentrauion does not favour plantlet growth. The hormonal content of a culture medium is crucial for any sustained growth of the culture. The growth and development of higher tissues in- vitro, especially during callogenesis in various concentration mixtures, is controlled by gradients of endogenous plant growth substances[11] .

This reiterates the role of growth hormones and more importantly their concentration in the media.

\section{Conclusion}

Plant regeneration through in- vitro tissue culture remains necessary for most genetic manipulation of plants and subsequent benefits for plant breeding . [ 7], Therefore, having standardized a suitable media for this particular species a definite protocol for all further, related study can be added. Besides the in-vitro multiplication may serve as a perennial source for the isolation of bioactive compounds [13]. This family has been used for extraction of many phenolic compounds, alkaloids, LSD etc. and the rapid growth of these plants in-vitro will prove to be beneficial.

\section{Journal reference:}

\section{References}

[1] J.N Oggema, M G Kinyua, J P Ouma and J O Owuoche, Agronomic performance of locally adapted sweet potato(Ipomoea batatas (L)Lam.) cultivars derived from tissue culture regenerated plants. African Journal of Biotechnology.Vol 6,(12) ,pp-1418-142,June 2007.

[2] Marilena Meira et.al (2012). Revista Brasileira de Farmacognosia. Vol.22.

[3] Pratibha Singh,K.N. Pandey, Vishal Verma, Vijai Kumar, H.P.Bhartiya. Extraction and Identification of Compound Derived from Ipomoea palmata Through Various Spectroscopic Techniques. Journal of Pharmacognosy and Phytochemistry. Vol.1 No. 62013.

[4] Tanmoy Sinha and A. Bandyopadhyay, Induction of callogenesis in Ipomoea obscura (L.) KerGawl, a little known medicinal plant, African Journal of Biotechnology Vol. 10(82), pp. 19161-19166, 19 December, 2011

[5] Rolando Izarraga, Ana Prnta, Nelson Espinoza, John H.Dodds. Tissue Culture of Ipomoea batatas: Micropropagation and Maintenance (1992) CIP Research Guide. 32. International Potato Centre, Lima, Peru.21p.

[6] Archana G Nair, S Pradeesh, G S Nikhila, G Sangeetha, I Mini and T.S.Swapna (2013) In-vitro propagation of a rare medicinal fern of Western Ghats, Indian Journal of Experimental Biology. Vol 51,pp919-923.

[7] Y. Henry,', P. Vain' \& J . De Buyser' . Genetic analysis of in-vitro plant tissue culture responses and regeneration capacities . Euphytica 79 : 45-58, (1994)Kluwer Academic Publishers. Printed in the Netherlands

[8] K.Padmanabhan, D.Cantliffe. K.E.Koch. Auxin- related gene expression and embryogenic competence in callus cultures of sweetpotato, Ipomoea batatas(L.) Lam. Plant Cell Reports. [2001] Vol 20,187-192.

[9] R. Awati, A. Mungole, S. Dey, A. Chaturvedi, P. Zanwar .In-vitro callus induction and shoot regeneration in Ipomoea obscura (L.): potent Indian medicinal plant. Indian Journal of Science and Technology. Vol,2, issue 8(Aug 2009)

Books:

[10] Roberta H.Smith .(2005) Plant Tissue Culture-Techniques and Experiments, $2^{\text {nd }}$ ed., Texas A\&M University, College Station, Texas. Academic Press. An Imprint of Elsevier, San Diego California,U.S.A

[11] Kalyan Kumar De (2008) An introduction to Plant Tissue Culture, $7^{\text {th }}$ ed.,Darjeeling Govt.College, Darjeeling,India. New Central Book Agency(P) Ltd. Kolkota, India.

[12] Narayanaswamy S (2005). Plant cell and tissue Culture, Tata Mc-Graw Hill publishing Co.Ltd. 6th reprint.

\section{Further Reading}

O.L.Gamborg and G.C. Phillips(1996)Plant Cell, Tissue and Organ Culture-Fundamental Methods, $6^{\text {th }}$ ed., Belmont U.S. First Narosa Publishing House. Sixth reprint 2010.

S.S. Bhojwani, M.K. Razdan(1996) - Plant Tissue Culture: Theory and Practice. Elsevier, a division of Reed Elsevier India Private Limited. 